\title{
O GASTRÓPODE Bradybaena similaris (Férussac, 1821) (Pulmonata, Xanthonychidae) COMO MODELO EXPERIMENTAL PARA ESTUDO EM LABORATÓRIO
}

\author{
Marcelo Nocelle de ALMEIDA ${ }^{1 *}$ \& Inês Scassa AFONSO-NETO ${ }^{2}$ \\ ${ }^{1}$ Universidade Federal Fluminense, Instituto do Noroeste Fluminense de Educação Superior, Departamento de \\ Ciências Exatas, Biológicas e da Terra. Santo Antônio de Pádua, Rio de Janeiro, Brasil. \\ ${ }^{2}$ Universidade Presidente Antônio Carlos. Juiz de Fora, Minas Gerais, Brasil. \\ *Autor para correspondência: mnocelle@vm.uff.br
}

http://dx.doi.org/10.18571/acbm.083

\section{RESUMO}

Entre as dificuldades enfrentadas pelos alunos nos cursos de ciências biológicas é a transformação de conhecimentos adquiridos nos conteúdos teóricos acadêmicos em conteúdos inteligíveis nos cursos da educação básica bem como uma interligação entre cotidiano e prática extraída desses conteúdos. Por outro lado, os alunos terão um aprendizado mais efetivo se puderem valer-se de metodologias que permitam um intercâmbio entre os conteúdos acadêmicos e a possibilidade de uma aplicação desses conteúdos em situações cotidianas. O presente trabalho tem por objetivo descrever uma metodologia que permita desenvolvimento de aspectos interdisciplinares. É um trabalho indicado para ser aplicado com alunos de graduação do curso de Ciências Biológicas utilizando o gastrópode terrestre Bradybaena similaris (Férussac, 1821) como modelo. Discute-se nesse trabalho a fisiologia do crescimento e da reprodução, a genética, ecologia e o comportamento dessa espécie. Ao final propõe-se uma metodologia de discussão e exposição dos resultados obtidos.

Palavras-chave: interdisciplinaridade; gastrópode terrestre; trabalhos práticos.

\begin{abstract}
Among the difficulties faced by students in courses in biological sciences is the transformation of theoretical knowledge acquired in academic content into intelligible content in courses of basic education as well as a connection between everyday life and practice drawn from these contents. Furthermore, students will have a more effective learning if they can draw on methodologies that allow an exchange between academic content and the possibility of applying such content in everyday situations. This paper aims to describe a methodology that enables the development of interdisciplinary aspects. It's a job specified to apply to graduate students in Biological Sciences course using the terrestrial gastropod Bradybaena similaris (Férussac, 1821) as a model. We discuss in this work the physiology of growth and reproduction, genetics, ecology and behavior of this species. At the end we propose a methodology for discussion and display of results.
\end{abstract}

Keywords: interdisciplinarity; terrestrial gastropods; pratical works.

\section{Introdução}

No início do século XIX, a necessidade de especialização demandada pelo processo de produção industrial induziu a diferenciação do conhecimento em disciplinas autônomas. Assim, as técnicas e os saberes foram progressivamente se diferenciando, configurando campos específicos de conhecimento com objetos próprios. Nessa perspectiva as universidades vêm 
produzindo ao longo de décadas um enorme acúmulo de conhecimentos fragmentados e compartimentalizados em diferentes disciplinas e especialidades que se ignoram, embora muitas vezes trabalhem com o mesmo objeto de estudo.

As situações descritas acima conduzem o educando a uma percepção unilateral dos conteúdos, o que particularmente em alunos de Ciências Biológicas tem se tornado um elemento responsável por deficiência em sua formação como futuros mestres dos ensinos fundamental e médio. Esses biólogos/mestres responsáveis pela condução do processo educacional formal em instituições públicas e particulares dos ensinos fundamental e médio tendem a não conduzir os seus alunos a observar os conceitos sob vários ângulos e contextualizados o que tem se tornado um fator de desestímulo nessas escolas.

Ainda hoje, grande parte dos livros didáticos disponíveis no mercado brasileiro organizam seus conteúdos de forma linear e fragmentada, induzindo por parte dos alunos, a memorização, repetição de conceitos e sem nenhuma contextualização, impedindo uma perspectiva interdisciplinar (VASCONCELOS e SOUTO, 2003).

É nesse contexto educacional que surge a ideia de aplicação de trabalhos práticos interdisciplinares em cursos de Ciências Biológicas e Ciências Naturais, e que venham conduzir uma interação entre diversas disciplinas, implicando em uma troca de conhecimentos, reunindo estudos diferenciados em um contexto coletivo de pesquisa. A interação proporciona um enriquecimento recíproco, com transformações em diferentes aspectos, como, nas metodologias de pesquisa, na leitura dos conceitos, na formulação de problemas e nos instrumentos de análise.

A inclusão da problematização e da experimentação no ensino de ciências poderá desenvolver o pensamento lógico e estimular o aluno vivenciar o método científico (RODRIGUES, 2009). Dentre essas metodologias, pode-se destacar os centros de interesse, temas geradores, projetos de trabalho e resolução de problemas. A metodologia baseada nos centros de interesse defende que o ponto de partida para o processo educativo é o conhecimento dos fatos mais próximos do cotidiano do aluno. Os projetos de trabalho são fundamentados na proposição que o aluno vai para a escola resolver os problemas enfrentados em seu dia a dia. $\mathrm{O}$ estudo que compreende o fazer e o pensar, o agir e o refletir, a teoria e a prática está incluso na metodologia denominada de temas geradores (DELIZOICOV et al., 2011).

Contudo, a adoção dessa metodologia não é simples, pois, a maioria das escolas brasileiras não dispõe de laboratórios para aulas práticas e nem de equipamentos e/ou aparelhos suficientes para essas atividades. Para isso se tornar uma realidade é necessário buscar alternativas objetivando minimizar essas dificuldades e impedimentos. Esses entraves só poderão ser superados a partir da pesquisa e da experimentação de novas metodologias e de técnicas alternativas, que visam quebrar a rotina e buscar ferramentas que permitam ao aluno visualizar de maneira ampla e inter-relacionada as teorias conceituais que lhe são ministradas. Aulas práticas de caráter interdisciplinar permitem motivar e despertar os interesses dos alunos desenvolverem a capacidade de observação, aproximar o aluno da realidade e contextualizar o ensino.

\section{Transposição didática, interdisciplinaridade e contextualização}

Durante os últimos 12 anos em que temos trabalhado no Ensino Superior, principalmente em cursos de formação de professores, ouvimos da maioria dos alunos universitários que as aulas que tiveram no Ensino Médio, sobretudo, na disciplina de biologia foram a mera leitura do livro didático. O reflexo dessa forma de "ensinar ciências" tem-se refletido em alunos sem nenhuma noção de método científico. Esse desconhecimento do caminho da elaboração dos conhecimentos científicos, e, principalmente, como foram transformados em conhecimentos escolares (transposição didática), tem feito com que os egressos dos cursos de formação de professores repitam, em sua vida profissional, os métodos utilizados com eles no passado. 
As próprias Universidades precisam rever sua forma de ensinar ciências, especialmente a biologia. Currículos fragmentados, disciplinas isoladas, seres vivos e fenômenos estudados a partir da decomposição de suas partes, como se cada uma funcionasse isoladamente (BRITO et al., 2008). Os livros de Ciências disponíveis no mercado brasileiro apresentam uma disposição linear de informações e fragmentação do conhecimento que limitam a perspectiva interdisciplinar, fundamentam cada vez mais o ensino na memorização e sem a menor contextualização, e, sobretudo, sem reflexão (VASCONCELOS e SOUTO, 2003).

O termo transposição didática foi cunhado por Michel Verret, em 1975, contudo foi amplamente divulgado por Yves Chevallard, utilizando-o na matemática. Atualmente, tem sido considerada como uma importante ferramenta para a melhoria do ensino em diversas áreas. A necessidade de ensinar o conhecimento leva à necessidade de modificá-lo. Assim, a transposição didática é o caminho pelo qual o conhecimento científico é transformado em conhecimento escolar, como um saber ensinado em sala de aula (NEVES e BARROS, 2011). Nesse contexto, tem sido dada muita ênfase ao resultado e não ao processo de transformação do saber científico em saber ensinado, o que limita o estabelecimento de relações cognitivas. Podemos utilizar os gastrópodes (caracóis ou caramujos) para ilustrar essa situação: gastrópodes marinhos depositam ovos, dos quais nascem larvas que após a metamorfose transformam-se em adultos. Os gastrópodes terrestres depositam ovos, dos quais nascem filhotes semelhantes aos adultos. Os alunos do ensino médio memorizam essas informações sem estabelecer as relações entre reprodução e ambiente em que os moluscos vivem.

A questão da fragmentação de conteúdos em qualquer área da ciência é uma constante no modelo cartesiano herdado por nossas academias. Segundo Pimenta (2008) aprendemos a disciplinaridade e a mantemos como modo dominante de fazer ciência e especialização científica. Sem dúvida há uma praticidade nesse modelo, no entanto haverá uma necessidade decorrente do mesmo que é a elaboração de leituras intertextuais. Portanto, há uma busca por trabalhos e atuações, principalmente em professores de cursos de licenciaturas, que privilegiem uma metodologia interdisciplinar. Há também um emaranhado de concepções sobre o trabalho interdisciplinar. Para se desenvolver um trabalho de característica interdisciplinar há a necessidade de estabelecer claramente o objetivo do trabalho bem como sua visão da questão interdisciplinar.

Para Etges (1994) interdisciplinaridade seria um deslocamento de um sistema construído para outro permitindo o aparecimento de linguagem mediadora entre diferentes áreas bem como entre ciência formal e senso comum não sendo mera busca de elementos comuns entre ciências.

Propostas interdisciplinares podem ser utilizadas para conduzir a interpretações e interrelações entre diferentes linguagens de subáreas de uma mesma área visando um reconhecimento do intertexto entre essas subáreas. Também podem ser aplicadas para permitir uma interligação contextual entre ciência e senso comum.

A interdisciplinaridade pretende que graduandos sejam conduzidos a realizar uma leitura perceptiva do intertexto das diferentes subáreas dentro de uma grande área ampliando a interpretação de um objeto de estudo bem como perceber as potenciais dificuldades vivenciadas por alunos da educação básica em ver o intertexto entre ciência formal e senso comum. Essa ampliação da leitura conceitual dentro de uma área pretende que graduandos de licenciatura visualizem através da superação de sua própria dificuldade de buscar linguagens mediadoras a necessidade de aplicação de metodologias que permitam e facilitem essa intertextualidade em sua atuação futura como mestres na educação básica.

Deve-se destacar também que a interdisciplinaridade permite ao graduando analisar as disciplinas enquanto isoladas e então perceber que a existência da disciplinaridade é fator importante para a colocação de conceitos que precisam ser decodificados isoladamente. E a partir dessa visão entender a necessidade de trabalhos que busquem a intercomunicação de 
linguagens permitindo uma intercomunicação textual facilitadora de entendimento amplo da realidade acadêmica e não acadêmica que o cerca.

Tem-se falado muito na contextualização do ensino, entretanto, a prática dessa contextualização tem sido feita de maneira equivocada, pois, sua efetivação tem sido feita de forma artificial, onde na maioria das vezes é citado um exemplo como forma de ilustrar um conteúdo ou um capítulo. Contudo, contextualizar o ensino é propor situações problemáticas reais, onde haja necessidade de buscar conhecimentos necessários para entendê-la e solucioná-la. Segundo a Lei de Diretrizes e Bases 9394/96, em seu artigo 2º , inciso XI, a educação escolar deve estar vinculada ao trabalho e as práticas sociais. Para que isso aconteça, os objetos de estudos das diferentes disciplinas devem ser articulados através da interdisciplinaridade e abordados de forma contextualizada. Isso permitirá ao aluno relacionar o trabalho ao seu cotidiano, além de compreender processos histórico, sociais, científicos e tecnológicos. Outro marco relevante acerca da interdisciplinaridade e contextualização é a Resolução $\mathrm{n}^{\mathrm{O}} 2$, de 30 de Janeiro 2012, que Define Diretrizes Curriculares Nacionais para o Ensino Médio. Segundo o Artigo 5ㅜㅡ. inciso VI, o Ensino Médio em todas as suas formas de oferta e organização, baseia-se na integração de conhecimentos gerais e, quando for o caso, técnico-profissional realizada na perspectiva da interdisciplinaridade e da contextualização.

Dentro dessa perspectiva contextualizada, essa metodologia de trabalho propõe a discussão de aspectos sócio científicos envolvendo questões científicas, ambientais, políticas, econômicas, éticas e culturais. Formulação de teste de hipóteses, condução de experimentos em laboratório, análise de fenômenos e formulação de conclusões, associado com as variáveis ambientais, são algumas questões científicas e ambientais envolvidas. A introdução de espécies exóticas invasoras, como Bradybaena similaris (Férussac, 1821), e suas consequências perpassam pelas esferas políticas e econômicas. Por fim, a utilização de animais como modelos biológicos são discussões éticas e culturais, que ultimamente muito tem se acirrado.

Esse trabalho objetiva mostrar aos alunos de Ciências Biológicas e Ciências Naturais, futuros professores dos ensinos fundamental e médio, uma forma prática de vivenciar o método científico, a transposição didática e a interdisciplinaridade. Promoverá a sua capacidade investigativa, a reflexão de seus métodos e, principalmente, tornar-se agente ativo na construção de seu conhecimento. Com essa metodologia, os alunos serão motivados ao prazer do aprendizado através de atividades intelectuais e sociais. É um trabalho prático que não utiliza "receitas prontas" de procedimentos cujos resultados são previsíveis, e, fundamentalmente, permitirá que os alunos entendam a Ciência como a construção de conhecimentos e não como pronta e definitiva.

\section{A questão da utilização dos animais na experimentação biológica e a bioética}

A utilização de animais em ambiente de laboratório vem sofrendo severas críticas em função dos métodos utilizados pelos professores/pesquisadores, pois, em sua maioria, os animais são dissecados, vivisseccionados e utilizados em testes de cosméticos, vacinas, medicamentos entre outros (MAGALHÃES e ORTÊNCIO-FILHO, 2006). Por outro lado, vários estudos, tanto em campo como em laboratório, têm demonstrado também a importância da utilização de animais como modelos didáticos, como por exemplo em ecologia de populações com besouros (Sitophilus oryzae Linnaeus, 1763 - Coleoptera, Curculionidae) (VITAL et al., 2004), biodiversidade com formigas (CORDEIRO et a., 2010) e ciclo circadiano com drosófilas (Drosophila melanogaster (Meigen, 1830 - Diptera, Drosophilidae) (AMORETTY et al., 2013).

No entanto, muitos profissionais têm defendido a abolição da utilização de animais em aulas práticas, demonstrações e pesquisas argumentando que essas condutas são antropocêntricas e antiéticas, além de causarem dor e sofrimento aos animais, principalmente em vertebrados. Afirmam ainda que a maioria dos animais são modelos inadequados para testes visando 
desenvolver técnicas e produtos para humanos, já que suas anatomias e fisiologias são relativamente diferentes, o que poderia provocar erros de inferência (FAGUNDES e TAHA, 2004; CORBI et al., 2011). Outra questão abordada por esses profissionais é o desconforto ético, moral e psicológico dos alunos ao executarem ou presenciarem aulas práticas e/ou demonstrações em que os animais são submetidos a práticas dolorosas (ARLUKE, 2004 apud MAGALHÃES e ORTÊNCIO-FILHO, 2006).

Diversos trabalhos têm sido publicados acerca de averiguações realizadas sobre a aceitação do uso de animais na docência e pesquisa, assim como a utilização de métodos alternativos por parte de professores, pesquisadores e alunos (FEIJÓ et al., 2008; TRÉZ e NAKADA, 2008; MELGAÇO et al., 2011; RODRIGUES et al., 2011). Há algumas discordâncias entre profissionais e alunos em relação ao tema. Enquanto alguns professores responderam que estão atentos ao bem estar animal outros desconsideram os aspectos legais e éticos ao uso de animais no ensino e na pesquisa, afirmando ainda que desconhecem métodos alternativos. Entre os alunos, alguns consideram importante utilizar animais na experimentação e no ensino, enquanto outros apresentam sensações negativas diante de animais mortos nas aulas.

Os métodos alternativos mais citados em substituição ao uso de animais em aulas práticas e/ou demonstrações, principalmente em Cursos de Medicina Humana e Veterinária, Farmácia e Biomedicina são softwares de simulação, vídeos, manequins, simuladores de plástico e poliuretano inodoro e animais preservados (MAGALHÃES e ORTÊNCIO-FILHO, 2006; ESCOSTEGUY e NOBRE, 2007).

Por outro lado, há estudos demonstrando que a interação homem-animal contribui para o processo de recuperação de crianças hospitalizadas, aumenta a integração entre alunos em uma sala de aula, refletindo em maior disposição a realização de tarefas e facilita o aprendizado (SEMINOTI \& FARACO, 2004). Ainda de acordo com os autores, as atividades mediadas por animais contribuem para aumentar os processos de grupo, facilitam as relações entre seus membros e gera novas organizações grupais.

Toda essa discussão é extremamente válida e contribui para o aprimoramento docente e científico de pesquisadores, professores e alunos que serão futuros professores também. Assim, acreditamos que essa proposta de trabalho não só contribuirá para o desenvolvimento dos alunos tanto no campo da pesquisa quanto na docência, em várias aspectos tais como questões éticas, morais, vivência e trabalho de grupo, e, respeito aos animais.

Esse trabalho propõe uma metodologia baseada na observação de diversos parâmetros biológicos, ecológicos e comportamentais de gastrópodes vivos. Cabe salientar que essa metodologia não propõe nenhum tipo de vivissecção, dissecação, injeção de drogas e privação de água, alimento ou espaço físico. Outro aspecto que deve ser ressaltado nessa proposta de trabalho é a preservação do direito ao consentimento de cada aluno participar ou não das atividades, pois, mesmo sem preconizar nenhum tipo de maus-tratos aos animais envolvidos, algum aluno poderá não se sentir à vontade em participar. Mesmo nessa situação, esse aluno ainda poderá participar de forma indireta, pois, como serão observados diversos tipos de dados, p. e., dados estatísticos, esse aluno poderá contribuir com o grupo analisando esses dados e simulando situações fictícias para o treinamento e aprimoramento do ensino multidisciplinar.

\section{0 gastrópode Bradybaena similaris (Férussac, 1821)}

Dentre os gastrópodes pulmonados terrestres, B. similaris é uma das espécies mais comuns no Brasil. É originário do sudeste da Ásia (região da China) e foi introduzido em várias regiões tropicais do mundo, inclusive no Brasil, através do comércio de plantas (PURCHON, 1968). No Brasil encontra-se amplamente disseminado, ocorrendo nos estados do Amapá, Bahia, Espírito Santo, Minas Gerais, Paraná, Rio Grande do Sul, Rio de Janeiro, Santa Catarina e São Paulo. É ideal para pesquisas científicas, pois apresenta manejo simplificado, alta taxa 
reprodutiva e eficiente criação em laboratório (ASAMI e OHBAYASHI, 1999). Essa espécie constitui um excelente modelo para experimentação animal em estudos de fisiologia (MOREIRA et al., 2003; GARCIA e PINHEIRO, 2007;), comportamento (LEAHY, 1984), ecologia, genética, microevolução (KOMAI \& EMURA, 1955; ASAMI e OHBAYASHI, 1999) e relação parasito/hospedeiro (PINHEIRO e AMATO, 1995). Esses fatos o tornam ideal para pesquisas científicas, pois apresenta manejo simplificado, alta taxa reprodutiva e eficiente criação em laboratório.

\section{Referencial teórico para suporte da proposta}

\subsection{Crescimento}

O crescimento nesta espécie pode se dividido em três fases: um crescimento lento na fase inicial (primeiros 15 dias), um crescimento rápido na segunda fase (até aos 105 dias) e novamente um crescimento mais lento na terceira fase (ALMEIDA e BESSA, 2001). Bradybaena. similaris continua a crescer após a maturidade sexual, entretanto, esse crescimento na fase adulta é muito menos pronunciado que na fase juvenil (CARVALHO et al., 2008). O crescimento em moluscos terrestres pulmonados é dependente de vários fatores, entre eles, alimentação (BRANDOLINI e GOMES, 2002), temperatura (HYMAN, 1967), umidade do substrato (D'ÁVILA et al., 2004), tipo de substrato (JUNQUEIRA et al., 2008), e densidade populacional (ALMEIDA e BESSA, 2000).

\subsection{Genética}

Os moluscos pulmonados terrestres têm muitas vantagens para estudos em genética e microevolução. Eles são freqüentemente diversos dentro e entre populações, tem movimentos lentos, são de fácil captura, tolerantes as condições de laboratório e facilmente marcados. Tais características têm despertado o interesse nesses animais para práticas em genética de populações (KOMAI e EMURA, 1955; CLARKE et al., 1978). Um dos principais padrões nesse grupo de moluscos é o polimorfismo. Segundo Backeljau et al. (2001), o polimorfismo em gastrópodes terrestres envolve a coloração externa da concha e do corpo, padrão de pigmentação, faixas e morfologia da concha. Dentre essas características polimórficas, a coloração e a presença ou ausência de faixas na concha, estão presentes em grande número de pulmonados terrestres. A concha de B. similaris apresenta cor variando de amarelo a marrom, com ou sem uma faixa de coloração castanha, que acompanha a sutura no seu limite superior e se estende na volta corporal até o bordo da abertura, sendo visível também pela face interna da concha (Figura 1). Esses caracteres, cor e faixa, são determinados geneticamente. $O$ gene para cor marrom $\left(\mathrm{c}^{\mathrm{B}}\right)$ é dominante sobre o gene para cor amarela (c), e o gene para a presença de faixa (s) é dominante sobre o gene para ausência de faixa $\left(\mathrm{s}^{+}\right)$(Tabela 1). Os dois loci são ligados. 


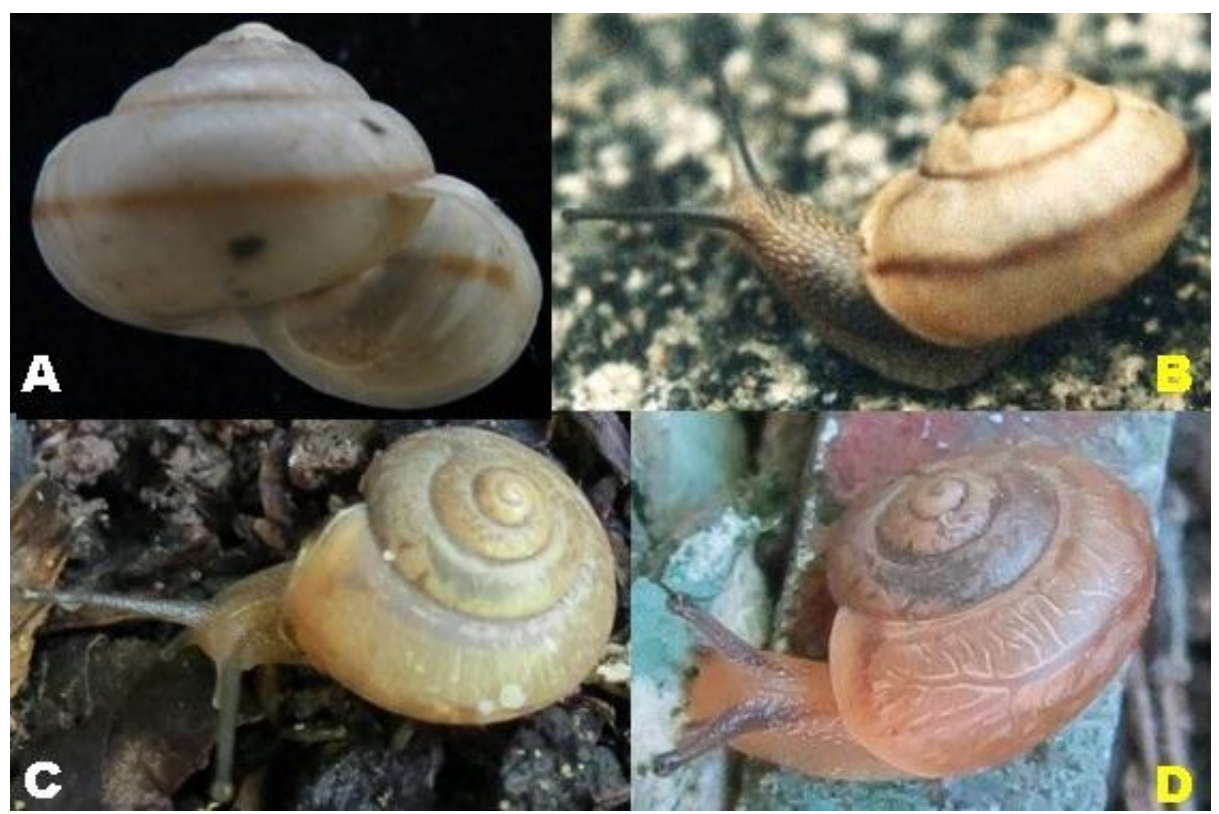

Figura 1: Fenótipos da concha de Bradybaena similaris (Férussac, 1821): amarela com faixa (A), marrom com faixa (B), amarela sem faixa (C) e marrom sem faixa (D). Fonte: arquivo pessoal do primeiro autor.

Tabela 1: Genótipos e fenótipos de Bradybaena similaris (Férussac, 1821) para as características cor e faixa na concha.

\begin{tabular}{cc}
\hline Genótipos & Fenótipos \\
\hline$c^{\mathrm{B}} s / c^{\mathrm{B}} s-c^{\mathrm{B}} s / c s-c^{\mathrm{B}} s / \mathrm{cs}^{+}-\mathrm{c}^{\mathrm{B}} \mathrm{s} / \mathrm{c}^{\mathrm{B}} \mathrm{s}^{+}-\mathrm{c}^{\mathrm{B}} \mathrm{s}^{+} / \mathrm{cs}$ & Marrom com faixa \\
\hline $\mathrm{c}^{\mathrm{B}} \mathrm{s}^{+} / \mathrm{c}^{\mathrm{B}} \mathrm{s}^{+}-\mathrm{c}^{\mathrm{B}} \mathrm{s}^{+} / \mathrm{cs}^{+}$ & Marrom sem faixa \\
\hline $\mathrm{cs} / \mathrm{cs}-\mathrm{cs} / \mathrm{cs}^{+}$ & Amarela com faixa \\
\hline $\mathrm{cs}^{+} / \mathrm{cs}^{+}$ & Amarela sem faixa \\
\hline
\end{tabular}

\subsection{Comportamento}

Os moluscos exibem atividades principalmente no período noturno, em função da temperatura e da umidade relativa do ar, pois diminui do risco de dessecação. Esta atividade noturna foi observada em B. similaris por vários autores (OLIVEIRA et al., 1971; SANTOS, 1982; THOMÉ et al., 1996; ALMEIDA e BESSA, 2001). Durante o dia, em geral encontram-se abrigados na face inferior de folhas, na base da vegetação rasteira de plantas ornamentais e legumes (LEAHY, 1984). Em laboratório, os animais ficam inativos, preferencialmente aderidos às laterais e a tampa dos recipientes (ALMEIDA e BESSA, 2001), pois exibem tropismo positivo por superfícies verticais (D`ÁVILA et al., 2004).

\subsection{Reprodução}

A maioria dos moluscos terrestres é ovípara. Freqüentemente depositam seus ovos em cavidades úmidas no solo. Esta cavidade (ninho) é consolidada com muco que protege os ovos de bactérias e fungos. O ninho é escavado pelo próprio molusco, utilizando o pé para tal função. $\mathrm{O}$ animal prende porções de terra com a região anterior do pé, conduzindo-as para fora do local 
com movimentos laterais da cabeça. À medida que a cavidade vai aumentando, o material escavado é conduzido para fora com movimentos ondulatórios da sola do pé. A profundidade do ninho de B. similaris varia segundo Leahy (1984) de 1,0 a $1,5 \mathrm{~cm}$, e de acordo com Almeida e Bessa (2001), entre 0,5 a 3,0 cm. Quanto ao horário de postura, Leahy (1984) afirmou que as oviposturas de $B$. similaris são realizadas preferencialmente no período diurno, enquanto que Almeida e Bessa (2001) observaram a realização de oviposições apenas no período noturno. A oviposição é aglomerada e envolvida por uma fina camada mucosa. Após a oviposição, o ninho é fechado pelo animal (LEAHY, 1984).

\section{Metodologia de trabalho com os animais em laboratório}

\subsection{Coleta}

Os moluscos dessa espécie podem ser coletados em lugares úmidos de hortas ou jardins, principalmente nos meses quentes e chuvosos do ano. Durante o dia ficam fixados à face inferior de folhas ou embaixo de objetos caídos, e a noite acima do nível do solo ou nos caules de plantas (LEAHY, 1984; THOMÉ et al., 1996).

\subsection{Manutenção em laboratório}

A manutenção da colônia pode ser feita em diversos tipos de materiais, tais como aquários (LEAHY, 1980, 1984; LOUREIRO, 1960), potes de plástico ou vaso de argila (ASAMI e OHBAYASHI, 1999). Dentre esses, as caixas retangulares de plástico de $30,0 \mathrm{~cm}$ de comprimento, $25,0 \mathrm{~cm}$ de largura e $11,0 \mathrm{~cm}$ de altura (THOMÉ et al., 1996) são ideais em função da durabilidade e fácil manejo. Essas devem ser fechadas com tela para silk screen para ventilação e evitar a entrada de moscas, principalmente da espécie Megaselia scalaris (Loew, 1866) (Diptera: Phoridae), cujas larvas são parasitóides de moluscos (LOUREIRO, 1960; IDRIS e ABDULLAH, 1997). Como substrato pode ser usado terra ou areia. Todavia, recentemente tem se preferido areia em função de que nesse substrato os moluscos apresentam menor índice de mortalidade e maiores índices de crescimento e reprodução (JUNQUEIRA et al., 2008). Esse substrato deve ser esterilizado a $120^{\circ} \mathrm{C}$ por uma hora (ALMEIDA e BESSA, 2001). Uma camada de aproximadamente $3,0 \mathrm{~cm}$ de substrato é suficiente para os terrários. Como os moluscos são muito dependentes da umidade, o substrato deve ser mantido sempre úmido, e a forma mais simples e eficiente de manter o substrato úmido é aspergir água com um borrifador manual. É preciso ter cautela com a quantidade de água aspergida no substrato, pois em excesso, os moluscos não se alimentam e nem se reproduzem.

Os moluscos devem ser alimentados com alface (Lactuca sativa Linnaeus, 1753) e com ração para codorna de postura em produção, peneirada em peneira com malha de $1,0 \mathrm{~mm}$, enriquecida com carbonato de cálcio (na proporção de 3:1). Essa ração não deve ser colocada diretamente no substrato, pois haverá uma grande proliferação de bactérias e fungos nocivos aos caramujos devido à umidade do ambiente. A ração deve ser colocada em algum tipo de recipiente que pode ser conchas de bivalves (OLIVEIRA et al., 1968), recipientes plásticos (tampas de frascos de medicamentos) (ALMEIDA e BESSA, 2001) ou em vidros de relógio (ASAMI e OHBAYASHI, 1999). A quantidade de alimento deve ser suficiente para todos os moluscos do terrário, pois do contrário haverá competição por alimento e isto influenciará nas avaliações experimentais. Asami e Ohbayashi (1999) utilizaram cerca de 1,0 g de ração para cada dois animais. Os terrários devem ser limpos para a retirada de fezes e restos de alimentação. Isso pode ser feito com papel toalha ou com uma colher. 


\section{Proposta da metodologia de trabalho}

A proposta aqui apresentada visa integrar as disciplinas ecologia, genética, fisiologia, comportamento animal e estatística. Para tanto, é necessário manter os moluscos em certas condições experimentais que irão gerar dados para que os professores das referidas disciplinas integrem os conceitos teóricos a prática observada pelos alunos.

\subsection{Observações de parâmetros relativos a cada disciplina}

Dentro da disciplina fisiologia animal, os fatores observados serão o ritmo de crescimento da concha e a reprodução. Na disciplina genética observar-se-á a transmissão de características hereditárias como a coloração da concha (amarela ou marrom) e a presença ou ausência de uma faixa castanha na volta corporal. A ecologia poderá abordar aspectos tais como os efeitos de grupo e de massa, bem como a competição intra-específica. Ainda pode ser observada na ecologia a influência das variáveis abióticas (temperatura, umidade relativa do ar e do substrato) nos parâmetros biológicos como crescimento, reprodução e sobrevivência. Para observação de características etológicas a própria manutenção dos moluscos em laboratório fornecerá dados sobre o comportamento dessa espécie em condições artificiais, que poderão ser comparadas com o comportamento dos moluscos em condições naturais.

\subsection{Metodologias de manutenção dos moluscos e parâmetros observados}

Para verificar os parâmetros biológicos citados acima, os moluscos devem ser mantidos de diversas maneiras como demonstradas na Figura 2.

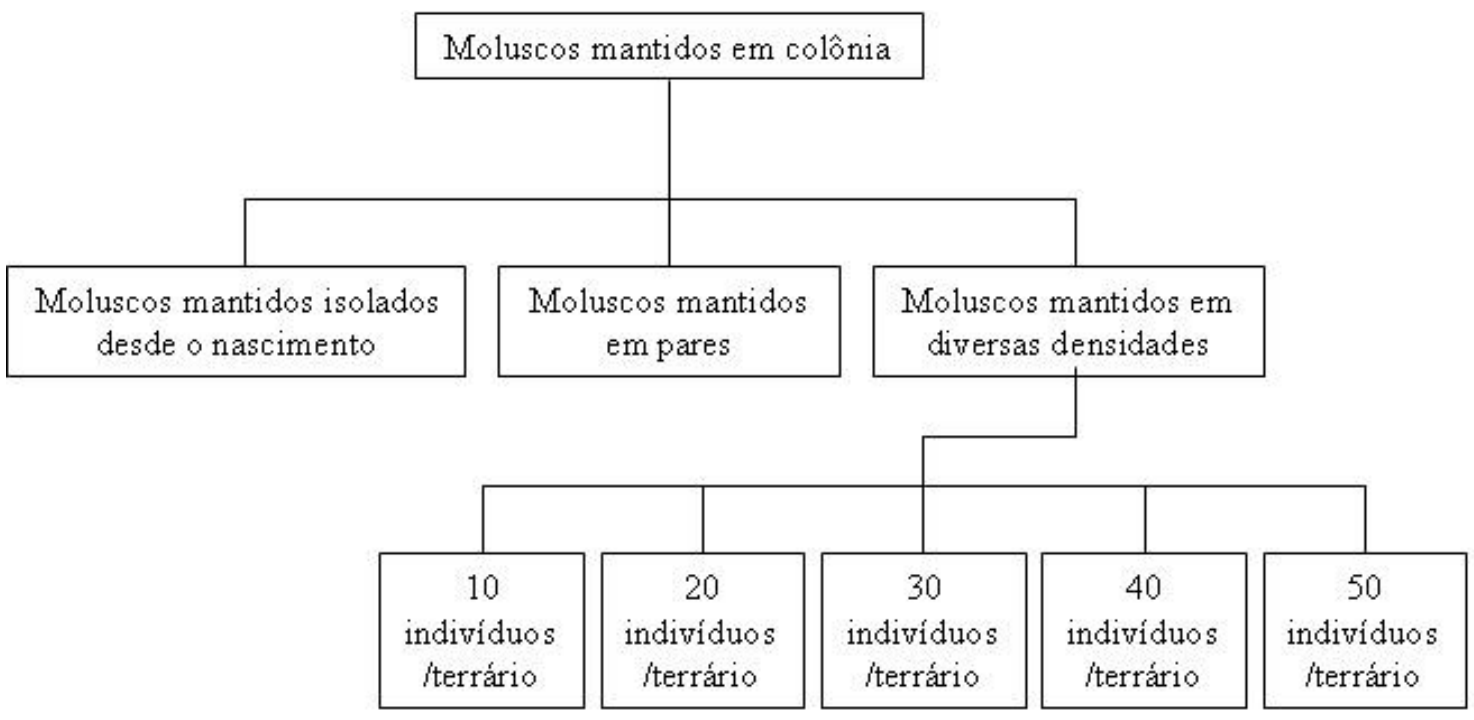

Figura 2: Metodologia de manutenção dos moluscos em laboratório.

A manutenção dos moluscos em isolamento desde o nascimento permitirá observar o crescimento da concha (sem competição alimentar), o comportamento sem a presença de coespecíficos, a herança genética e a reprodução, a partir de um único organismo doador de genes através da reprodução por autofecundação. Para avaliar o crescimento, os moluscos devem ser medidos (diâmetro maior da concha) quinzenalmente com um paquímetro (Figura 3) (ALMEIDA e BESSA, 2001). Essa espécie de molusco se reproduz tanto por autofecundação quanto por fecundação cruzada (ALMEIDA e BESSA, 2001). A maturidade sexual que ocorre em torno de 109 dias de vida (ALMEIDA e BESSA, 2001). Ainda sobre a reprodução poderá ser 
observado o tempo de alcance da maturidade sexual, a produção de ovos por indivíduo e o intervalo entre posturas.

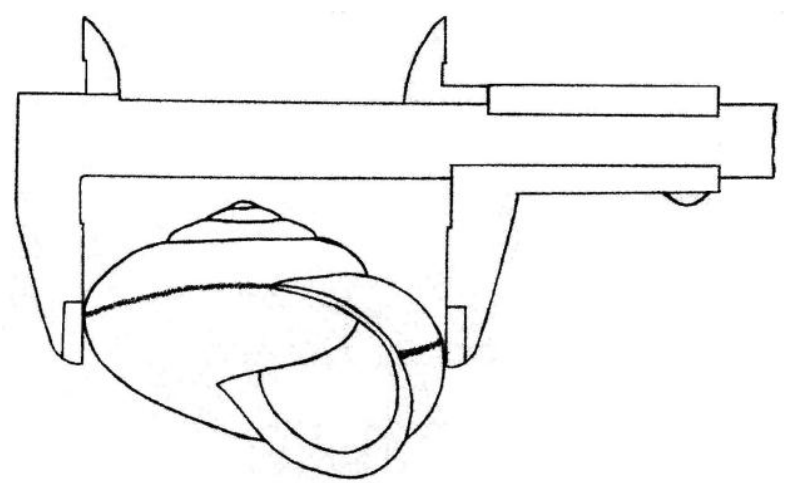

Figura 3: Medida do diâmetro maior da concha de Bradybaena similaris (Férussac, 1821).

Os moluscos mantidos em pares permitirão observar o modo habitual de reprodução, se por autofecundação ou fecundação cruzada. Os indivíduos com concha amarela sem faixa exercerão a função de marcador genético para distinguir os indivíduos produzidos por autofecundação daqueles produzidos por fecundação cruzada. O genótipo amarela sem faixa é totalmente recessivo, portanto um indivíduo com esse genótipo será necessariamente homozigoto e produzido exclusivamente por autofecundação.

Os moluscos mantidos em diversas densidades populacionais permitirão observar o efeito do número de indivíduos sobre o comportamento, o crescimento e a reprodução. Entretanto, é importante observar que a quantidade de alimento poderá influenciar em todos esses parâmetros biológicos. Assim, se utilizarmos a proporção de 1,0 g de ração para cada dois animais, descrito anteriormente, será necessário adequar à quantidade de ração em cada terrário. Pode-se também nessa metodologia avaliar a influência da quantidade de alimento sobre os parâmetros citados acima. Vale ressaltar também que o espaço que cada indivíduo tem nos terrários com diversas densidades também poderá influenciar nos resultados finais. Dessa forma, esse é outro parâmetro que ser deve adequado as diversas densidades. Assim como em relação ao alimento, esse também pode ser um parâmetro observado, ou seja, o quanto a área disponível influencia no crescimento e na reprodução.

\subsection{Tempo de incubação dos ovos}

Os ovos encontrados nos terrários devem ser removidos com auxílio de um pincel macio e colocados em outro terrário com as mesmas características do terrário de origem. Deverão ser mantidos juntos no fundo do recipiente, cobertos com uma camada de substrato mantido levemente úmido. Essa metodologia permitirá observar o período de incubação e a taxa de eclosão de filhotes. Segundo Almeida e Bessa (2001), o tempo médio para eclosão dos jovens é de 23,6 dias, contudo pode variar entre 14 e 35 dias, dependendo da temperatura e umidade do substrato.

\subsection{Observações sobre a coleta e o descarte dos animais}

A autorização para coleta de material zoológico destinado a fins científicos ou didáticos é regulada pela Portaria n 332 - IBAMA, de 13 de março de 1990 e regulamentada pela Instrução Normativa 154/2007 - IBAMA. Para obter tal autorização é necessário enviar o projeto de pesquisa ou didático para o IBAMA. Todo o procedimento também deve ser aprovado pelo 
Comitê de Ética em Pesquisa Animal da instituição, bem como deve ser indicado em qual coleção científica o material de referência deverá ser tombado. Cabe aqui ressaltar que a metodologia de trabalho apresentada nesse artigo não propõe nenhum tipo de experiência dolorosa ou cruel, assim como não objetiva à vivissecção, privação de alimentos e nem a administração de qualquer tipo de droga. Essa espécie tem um ciclo vital médio de 144 dias, podendo alcançar até 488 dias (CARVALHO et al., 2008). Dessa forma, não é necessário sacrificar os animais ao final do trabalho, pois, devido ao seu ciclo de vida, a morte ocorrerá naturalmente. Entretanto, se houver necessidade de conservá-lo após o final do trabalho, pode ser fixado em líquido de Railliet-Henry e posteriormente conservado em álcool $70^{\circ}$ glicerinado.

\subsection{Metodologia didática proposta}

Primeiramente cabe esclarecer que as metodologias por área sinteticamente delineadas constituem-se em norte para poder esclarecer a metodologia didática proposta no presente trabalho. A cada área (fisiologia, genética, ecologia, etologia e estatística) os professores podem usar metodologias em suas aulas e trabalhos práticos e/ou de campo com as quais estejam familiarizados ou ainda aquelas que melhor atendam as particularidades de seu curso, período ou instituição.

A metodologia didática proposta visa permitir o desenvolvimento no acadêmico de três habilidades: socialização, contextualização e organização. A socialização permite o desenvolvimento de trabalhos em equipes conduzindo os estudantes dos cursos de Ciências Biológicas e Ciências Naturais delinearem e organizarem os dados obtidos de maneira diferenciada e discuti-los com o grupo e com outros não pertencentes ao grupo acadêmico, bem como agrupar dados variados transformando-os em leitura inter-relacionada e inteligível.

A contextualização visa utilizar os dados e resultados acadêmicos para entender, explicar e resolver as situações do dia a dia e responder perguntas não acadêmicas. Transformar dados, resultados e conclusões para linguagem entendida pelo leigo e por alunos do ensino básico (fundamental e médio), além de entender e conseguir explicar a aplicabilidade desses dados e resultados em situações cotidianas.

A organização irá conduzir o acadêmico a elaborar a partir de dados de aulas práticas e de campo discussões de conceitos, análise de situações e possíveis soluções para problemas na forma de exposições gráficas e debates entre grupos e trabalho de orientação com respostas e soluções para situações cotidianas.

\subsection{Organização do trabalho}

Esse trabalho consta do aproveitamento de dados dos trabalhos propostos em cada disciplina prática no semestre letivo com a finalidade de expor esses dados aos alunos do curso, bem como de discuti-los, e transformá-los em informações de fácil leitura ao leigo ou aluno do ensino básico.

\subsection{Etapas}

a) Reunião de professores e monitores das disciplinas que desejam desenvolver a metodologia proposta.

b) Elaboração de cronograma comum e organograma de trabalho comum (apenas para a realização desse trabalho, não implica que todas as outras atividades das disciplinas envolvidas serão comuns).

c) Apresentação da proposta de elaboração e desenvolvimento do trabalho em sala de aula nas disciplinas envolvidas. O trabalho referente ao conteúdo da disciplina segue o modelo 
que o professor normalmente utiliza em sua disciplina e o professor explica como será feito esse trabalho e quais as datas de entrega. A diferença reside no fato de que será explicado que esse trabalho terá seus dados e resultados transformados para linguagem acessível à comunidade não acadêmica e os resultados e conclusões serão discutidos juntamente com resultados e conclusões obtidos em outras disciplinas e finalmente apresentados a apreciação coletiva. Esses dados e resultados podem ser expostos em mural periodicamente, e como conclusão do trabalho poderá haver uma discussão oral comum às disciplinas envolvidas e uma apresentação tipo pôster a todos os alunos do curso.

Deve-se esclarecer que esse é um trabalho acadêmico, porém, seu objetivo não será somente a coleta de dados, exposição de resultados e discussão de autores, mas também a transformação desses dados e resultados em linguagem legível para o leigo (aluno do ensino básico) bem como a discussão para contextualização desses dados tornando-os comuns às disciplinas e aplicáveis a situações do cotidiano.

Assim, sugere-se um mês de trabalho no campo ou laboratório, para coleta de dados e primeira observação de resultados. Um mês para exposição de dados e resultados parciais no mural (afixados no mural semanalmente ou quinzenalmente). Um a três dias para apresentação oral dos dados e resultados e emissão de conclusões comuns. Um dia para a exposição geral aos outros acadêmicos do curso para finalização do trabalho.

Para a organização do mural deve-se definir previamente sua localização e o espaço disponível e como serão expostos os dados e resultados. Cada grupo expõe os dados e resultados obtidos nas diferentes disciplinas, lembrando que os dados e resultados expostos deverão estar organizados e descritos de forma que o leigo os entenda. Dessa forma deve-se fazer a descrição dos fenótipos e não apenas colocar um quadro de genótipos, contendo ainda comentários que permitam que a família de um aluno do ensino básico consiga entender o que acontece com os caramujos de seu jardim. Ao final do período de exposição de dados e resultados, será desenvolvido um fórum de discussão.

O fórum de discussão deve acontecer com data já prevista anteriormente e consta de apresentação oral dos trabalhos dos diferentes grupos nas diferentes disciplinas. Essa apresentação é fechada para os alunos das disciplinas, professores e monitores. Essa etapa poderá constar de um a três dias dependendo do número de alunos e horário das disciplinas. Esse momento privilegia apresentações e conclusões conjuntas dos resultados da observação do objeto de estudo como um todo no ambiente.

De acordo com a organização inicial teremos os grupos de apresentação assim delineados: (1) mesmos alunos que façam duas ou mais disciplinas, podem montar um grupo fixo para todas as disciplinas e expor os resultados em uma única apresentação fazendo a ligação entre esses resultados (ex; dados da genética que expliquem os resultados da etologia e assim por diante), ou (2) grupos diversos de alunos de disciplinas diferentes podem apresentar dados em conjunto e expor resultados em uma única apresentação fazendo a ligação entre esses resultados. A definição dos grupos dependerá do número de alunos por disciplina, se ocorre coincidências de alunos por disciplina, disponibilidade de horário dos alunos para estudar e discutir e executar os trabalhos em horário extraclasse e conveniência de horário das próprias disciplinas. Ressaltase que mesmo que nesse momento exija-se do acadêmico uma apresentação com gráficos e discussão de autores (típica de trabalhos científicos), deverá haver uma parte dessa apresentação que mostre a transformação dos dados em dados legíveis pelo leigo e sua contextualização no cotidiano do cidadão. Ao final dessas apresentações são definidas conclusões gerais entrelaçando os trabalhos e definidas aplicabilidades desses dados em situações cotidianas.

Após a realização do fórum de discussão poderá ser organizada uma apresentação, em forma de banner, de resultados e conclusões principalmente aquelas retiradas do fórum (construídas em conjunto) a todos os alunos do curso. Realizada no período de um dia ou metade do dia, dependendo do número de alunos expositores e do horário de funcionamento do curso. 
Essa data e horário deverão ser divulgados e os alunos devem ser incentivados a visitar e questionar sobre os diversos temas para que realmente aconteça uma discussão acadêmica de conceitos e sua interligação, e a percepção da transformação em linguagem diversa daquela utilizada na academia. Os resultados e conclusões disponibilizados nessa etapa devem estar em linguagem acessível ao leigo e mostrando sua possível aplicabilidade em situações cotidianas.

\section{Considerações Finais}

Segundo Pimenta e Anastasiou (2010) em 1934 surgem os cursos de licenciatura em nosso país e a finalidade era oferecer formação pedagógica de suporte necessária aqueles que ensinam. Desde esse momento até hoje muitos licenciandos e também professores buscam por uma metodologia pronta que resolva todas as situações de ensino. Na prática do dia a dia é notório que tal fato não irá ocorrer, pois assim como todo o processo ensino aprendizagem as metodologias irão com certeza variar no espaço e no tempo de acordo com o contexto e com as interações oriundas do próprio conviver de professores e alunos.

Inúmeras são as críticas a produção de conhecimento científico como a fragmentação e a especialização sendo essas mesmas críticas também às disciplinas escolares (ciências e biologia são exemplo) relacionadas muitas vezes apenas ao processo de memorização (MARANDINO et al., 2009).

Esses hiatos ocorrentes no processo de difusão dos saberes acadêmicos até alcançar as disciplinas ministradas na educação básica remetem a questão das metodologias, onde se faz necessário um investimento por parte das licenciaturas para permitir mais flexibilidade nas formas de relacionar conteúdos vinculados ao mundo acadêmico (mais abstratos) a questões de caráter utilitário (cotidianas). Exemplificando, metodologias que privilegiem a interdisciplinaridade, que permitam uma forma de discussão desses conteúdos e que constituam elemento valioso a se explorar; pois as mesmas auxiliam a realização por educadores e educandos de interligação entre conceitos advindos de diferentes subáreas pertencentes a uma grande área de ensino; bem como entre diferentes áreas, a visões cotidianas de um objeto de estudo.

Observando-se as disciplinas escolares ciências e biologia, nota-se de uma maneira generalizada que a discussão do conteúdo é árdua e desvinculada de aplicações em situações cotidianas. Nessas disciplinas os professores (graduados em ciências biológicas) muitas vezes encontram-se presos a uma exposição de conteúdo de forma essencialmente acadêmica (gerando dificuldades de interligação ao mundo perceptivo do educando) ou apenas fazendo uma breve e inócua transformação para linguagem mais popular; sem permitir contextualização adequada a essa faixa etária e educacional (educação básica). Essa dificuldade de transmissão de informações não permite aos educandos uma visão crítica da dinâmica dos fenômenos vivos e da dinâmica da relação existente entre a ação antrópica e mundo vivo.

No entanto, que não se entenda serem as metodologias a solução final para o exercício da profissão de professor. Mas cabe perceber que há uma necessidade premente dos cursos de licenciatura em investir na proposição e execução de metodologias que poderão ser utilizadas e adaptadas em diferentes situações educacionais corroborando Marandino et al. (2009). As autoras destacam a necessidade de uma formação pré-profissional de suporte ao futuro docente permitindo-lhe uma gama de vivências para aplicá-las em sua ação profissional.

Aliado às questões citadas destaca-se o requisito; necessidade formadora para a cidadania na educação básica, apontado na LDBEN; PCN e CNEM. Essa formação para cidadania, em Demo (1997) e Brandão (2010), entendida como a formação do cidadão capaz de traduzir as informações recebidas para as diferentes situações vivenciadas reforçam a relevância de licenciaturas que promovam a formação pedagógica de suporte e isso passa pelo conhecimento e 
aplicação de diferentes metodologias de trabalho que permitam adequação do conteúdo abstrato e acadêmico ao ambiente escolar.

Sendo a educação uma prática social e capaz de transformar a percepção da realidade dentro dos contextos vivenciados justifica-se a pretensão de criar e expor metodologias como opção aos professores para a realização de sua prática educacional de transmissão/discussão de conteúdos. Pretendendo auxiliar os mestres a alcançarem de forma mais efetiva os alunos e favorecendo uma interpretação crítica da realidade complexa de hoje.

\section{Referências}

ALMEIDA, M. N.; BESSA, E. C. A. Efeito da densidade populacional sobre o crescimento e a reprodução de Bradybaena similaris (Férussac, 1821) (Mollusca, Xanthonychidae) e Leptinaria unilamellata (d'Orbigny, 1835) (Mollusca, Subulinidae). Rev. Bras. de Zoociências, v. 2, n. 1, p. $97-104,2000$.

ALMEIDA, M. N.; BESSA, E. C. A. Estudo do crescimento e da reprodução de Bradybaena similaris (Férussac, 1821) (Mollusca, Xanthonychidae) em laboratório. Revta. bras. Zool., v. 18, n. 4, p. 1115-1122, 2001.

AMORETTY, P. R.; PADILHA, K. P.; FREITAS, R. T.; BRUNO, R. V. Uso de Drosophila melanogaster como modelo para o estudo do relógio circadiano em insetos vetores. Acta Scientia \& Technicae, v. 1, n 1, p. 87-98, 2013.

ASAMI, T.; OHBAYASHI, K. Effects of oviposition substrate on lifetime fecundity of the terrestrial pulmonate Bradybaena similaris. J. Conch., v. 36, n. 5, p. 1-9, 1999.

BACKELJAU, T.; BAUR, A; BAUR, B. Population and conservation genetics. In: Barker, G. M. (Ed.). The biology of terrestrial molluscs. New York: Cabi Publishing, 2011. p. 383-412.

BRANDÃO, C. F. LDB passo a passo: Lei de Diretrizes e Bases da Educação Nacional, lei $\boldsymbol{n}^{o}$. 9394/96 comentada e interpretada, artigo por artigo. São Paulo: Avercamp, 2010.

BRANDOLINI, S. V. P. B.; GOMES, A. P. G. Influência de diferentes dietas sobre o crescimento, sobrevivência e reprodução de Leptinaria unilamellata (d’orbigny, 1835) (Gastropoda, Subulinidae) em laboratório. Rev. bras. Zoociências, v. 4, n. 2, p. 169-177, 2002.

BRASIL. Portaria $\mathrm{n}^{\circ}$ 332, de 13 de março de 1990. Diário Oficial da União. Brasília, DF, nº 54, Seção I, Pag. no 5690, de 20 mar. 1990.

Lei 9.394, 20 de dezembro, 1996. Brasília: Diário Oficial da União, v. 134, n. 248, p. 27833-841, 23 dez. 1996.

Instrução Normativa $\mathrm{N}^{\circ}$ 154, de 01 de março de 2007. Diário Oficial da União no 42, 2 de março de 2007, Seção 1, 57-59.

Resolução CNE/CEB n ${ }^{\circ}$ 2, de 30 de janeiro de 2012 - Define Diretrizes Curriculares Nacionais para o Ensino Médio. Diário Oficial da União. Brasília. DF, seção 1, p. 20, 24 de jan. 2012 . 
BRITO, L. D.; SOUZA, M. L.; FREITAS, D. Formação inicial de professores de ciências e biologia: a visão da natureza do conhecimento científico e a relação CTSA. Interacções, v. 9, p. 129-148, 2008.

CARVALHO, C. M.; BESSA, E. C. A.; D’ÁVILA, S. Life history strategy of Bradybaena similaris (Fèrussac, 1821) (Mollusca, Pulmonata, Bradybaenidae). Molluscan Research, v. 28, n. 3, p. 171-174, 2008.

CLARKE, B.; ARTHUR, W.; HORSELEY, D. T.; PARKIN, D. T. Genetic variation and natural selection in pulmonate molluscs. In: Fretter, V.; Peake, J. (Ed.). Pulmonates vol 2A, Systematics, evolution and ecology. London: Academic Press, 1978. p. 219-270.

CORBI, I. S. A.; SILVA, D. A.; LOPES, L. V. Reflexões acerca da validade do modelo animal como método científico: implicações éticas e metodológicas. J. Health Sci. Inst., v. 29, n. 1, p. 37-40, 2011.

CORDEIRO, R. S.; WUO, M.; MORINI, M. S. C. Proposta de atividade de campo para o ensino de biodiversidade usando formigas como modelo. Acta Scientiarum, Education, v. 32, n. 2, p. 247-254, 2010.

D’ÁVILA, S.; DIAS, R. J. P.; BESSA, E. C. A.; DAEMON, E. Resistência à dessecação em três espécies de moluscos terrestres: aspectos adaptativos e significado para o controle de helmintos. Rev. bras. Zoociências, v. 6, n. 1, p. 115-127, 2004.

DELIZOICOV, D.; ANGOTTI, J. A.; PERNAMBUCO, M. M. Ensino de Ciências: fundamentos e métodos. São Paulo: Cortez Editora, 2011.

DEMO, P. A nova LDB: ranços e Avanços. Campinas: Papirus, 1997.

ESCOSTEGUY, A.; NOBRE, F. G. A. O uso de animais pode ser evitado na educação? A Hora Veterinária, v. 160, p. 68, 2007.

ETGES, N. J. Estrutura versus subjetividade nas relações sociais: uma oposição de exterioridade? Educação e Realidade, v. 19, n. 1, p. 47-60, 1994.

FAGUNDES, D. J.; TAHA, M. O. Modelo animal de doença: critérios de escolha e espécies de animais de uso corrente. Acta Cirúrgica Brasileira, v. 19, n. 1, p. 59-65, 2004.

FEIJÓ, A. G. S.; SANDERS, A.; CENTURIÃO, A. D.; RODRIGUES, G. S.; SCHWANKE, C. H. A. Análise de indicadores éticos do uso de animais na investigação científica e no ensino em uma amostra universitária da Área da Saúde e das Ciências Biológicas. Scientia Medica, v. 18, n. 1, p. 10-19, 2008.

GARCIA, T. A.; PINHEIRO, J. The photoperiod may modulate the carboydrate metabolismo f Bradybaena similaris (Férussac, 1821) (Mollusca, Bradybaenidae). Rev. bras. Zoociências, v. 9, 1, p. 7-12, 2007.

HYMAN, L. H. The Invertebrates. Mollusca I. London: McGraw Hill, 1967. 
IDRIS, A. B.; ABDULLAH, M. The phorid fly, Megaselia scalaris (Loew), as candidate for managing molluscicide-resistatn round snail, Bradybaena similaris (Fèrussac). Resistant Pest Management, v. 92, p. 28-29, 1997.

JUNQUEIRA, F. O.; ARÉVALO, E. G.; BESSA, E. C. A. Influência do substrato sobre aspectos do ciclo de vida de Bradybaena similaris (Férussac, 1821) (Mollusca, Bradybaenidae), sob condições de laboratório. Revista Brasileira de Biociências, v. 6, n. 4, p. 347-354, 2008.

KOMAI, T.; EMURA, S. A study o population genetics of the polymorphic land snail Bradybaena similaris. Evolution, v. 9, p. 400-418, 1955.

LEAHY, W. M. Aspectos adaptativos de Bradybaena similaris Férussac, 1821 (Mollusca, Gastropoda, Pulmonata) submetido ao jejum e dessecação. Bol. Fisiol. Animal, Univ. S. Paulo, v. 5, p. 131-138, 1980.

LEAHY, W. M. Comportamento e características anatomofuncionais da reprodução em Bradybaena similaris (Molusco Pulmonado). Ciência \& Cultura, v. 36, n. 8, p. 1389-1392, 1984.

LOUREIRO, M. C. Manutenção de Bradybaena similaris (Férussac, 1821) em terrários. Revista Ceres, v. 11, n. 62, p. 60-63, 1960.

MAGALHÃES, M.; ORTÊNCIO-FILHO, H. Alternativas ao uso de animais como recurso didático. Arq. Ciênc. Vet. Zool. Unipar, v. 9, n. 2, p. 147-154, 2006.

MARANDINO, M.; SELES, S. E.; FERREIRA, M. S. Ensino de Biologia: histórias e práticas em diferentes espaços educativos. São Paulo: Cortez, 2009.

MELGAÇO, I. C. P. P. S.; MEIRELlES, R. M. S.; CASTRO, H. C. O uso de animais nas disciplinas de anatomia, fisiologia, imunologia e zoologia e suas implicações éticas e legais durante a educação científica. Revista Electrónica de Enseñanza de las Ciencias, v. 10, n. 3, p. 499-515, 2011.

MOREIRA, C. S. D. R.; GOMES, E. M.; CHAGAS, G. M.; PINHEIRO, J. Calcium changes in Bradybaena similaris (Férussac, 1821) (Mollusca, Xanthonychidae) under starvation. Rev. bras. Zoociências, v. 5, n. 1, p. 33-44, 2003.

NEVES, K. C. R.; BARROS, R. M. O. Diferentes olhares acerca da transposição didática. Investigações em Ensino de Ciências, v. 16, n. 1, p. 103-115, 2011.

OLIVEIRA, M. P.; ALMEIDA, E. L.; VIEIRA, I.; OLIVEIRA, M. H. R. Comunicação no1. Criação de moluscos em terrários e aquários: uma experiência em laboratório. Juiz de Fora. Esdeva, 1968.

OLIVEIRA, M. P.; VIEIRA, I.; OLIVEIRA, M. H. R. Sobre Bradybaena similaris Férussac (Gastropoda, Pulmonata, Stylommatophora, Fruticicolidae) Copula y funcionamiento del oviducto durante el periodo de fecundacion y formacion del huevo. Com. Soc. Malac. Urug., v. 3 , n. 21 , p. $155-161,1971$.

PIMENTA, C. Contributos para a elaboração de uma tese interdisciplinar. Ideação - Revista do Centro de Educação e Letras da UNIOESTE, v. 10, n. 1, p. 63-77, 2008. 
PIMENTA, S. G.; ANAStASIOU, L. G. C. Docência no Ensino Superior. São Paulo: Cortez Editora, 2010.

PINHEIRO, J.; AMATO, S. B. Eurytrema coelomaticum: influence of the infection on the reproduction and nucleic acids contents in the albumen gland and ovotestis of Bradybaena similaris. Mem. Inst. Oswaldo Cruz, v. 90, n. 5, p. 635-638, 1995.

PURCHON, R. D. The Biology of the Mollusca. Hungaray. Pergamon Press Ltda, 1968.

RODRIGUES, D. C. G. A. A Inserção de atividades experimentais no ensino de ciências em nível médio: um relato de sala de aula. Revista Práxis, v. 1, n. 2, p. 17-21, 2009.

RODRIGUES, G. S.; SANDERS, A.; FEIJÓ, A. G. S. Estudo exploratório acerca da utilização de método alternativos em substituição aos animais não humanos. Rev. bioét., v. 19, n. 2, p. 577596. 2011.

SANTOS, E. Moluscos do Brasil. Belo horizonte. Editora Itatiaia Ltda, 1982.

SEMINOTTI, N.; FARACO, C. B. Atividade mediada por animais: uma organizadora na sala de aula. A Hora Veterinária, v.141, p. 29-31, 2004.

THOMÉ, J. W.; SILVA, A. V.; SANTOS, D. D. Manual de aulas práticas de zoologia: estudo morfo-anatômico de um molusco Sigmuretra. Cadernos EDIPUCRS 12, Série Zoologia 2, 1996.

TRÉZ, T. A.; NAKADA, J. I. L. Percepções acerca da experimentação animal com um indicador do paradigma antropocêntrico-especista entre professores e estudantes de Ciências Biológicas da

UNIFAL-MG. Alexandria, Revista de Educação em Ciência e Tecnologia, v. 1, n. 3, p. 3-28, 2008.

VASCONCELOS, S. D.; SOUTO, E. O livro didático de ciências no ensino fundamental proposta de critérios para análise do conteúdo zoológico. Ciência \& Educação, v. 9, n. 1, p. 93104, 2003.

VITAL, M. V. C.; VIEIRA, L. C. G.; CARVALHO, R. A.; COSTA, D. A.; SILVA, L. C. F.; SILVEIRA, A. V. T.; LIMA FILHO, G. F. Insetos em experimentos de ecologia de populações: um exemplo de abordagem didática. Acta Scientiarum, Biological Sciences, v. 26, n. 3, p. $287-$ 290. 2004. 